\title{
Formulation and Antioxidant Activity Evaluation of Spondias mombin - Abelmoschus esculentus Mucilage Emulsion
}

\author{
Joseph O. Oiseoghaede ${ }^{1}$, Aminat A. Oyawaluja ${ }^{1}$, Olukemi A. Odukoya ${ }^{1}$, \\ Margaret O. Ilomuanya ${ }^{2}$, Oriyomi I. Yinusa ${ }^{1}$ and Omotayo K. Raji ${ }^{1}$ \\ ${ }^{1}$ Department of Pharmacognosy, Faculty of Pharmacy, University of Lagos, College of Medicine of the \\ University of Lagos campus, Idi-Araba, Lagos, Nigeria \\ ${ }^{2}$ Department of Pharmaceutics and Pharmaceutical technology, Faculty of Pharmacy, University of Lagos \\ College of Medicine of the University of Lagos campus, Idi-Araba, Lagos, Nigeria
}

(Received: July 22, 2020; Accepted: December 26, 2020; Published (web): January 28, 2021)

\begin{abstract}
Plant gums and mucilage have wide applications in pharmaceutical formulations as emulsifying agents. But these are quite costly, therefore there is always the need for cheaper alternatives. In this study, Okra mucilage from Abelmoschus esculentus (L.) Moench pods was used to formulate Spondias mombin L. leaf extract emulsion. The emulsion was assessed for the effect of the mucilage on antioxidant activity of the extract using four standard in vitro assays. Phytochemical screenings of the mucilage as well as physico-chemical and microscopic characterization of the emulsion were also carried out. The mucilage contained carbohydrates, reducing sugars, terpenoids and unsaturated lactones. The $\mathrm{pH}$ of the resulting emulsion was 6.88 . The size of the oil globules were small with the average size of $4.8 \mu \mathrm{m}$. The extract had superior 2,2-diphenyl-1-picrylhydrazyl (DPPH) radical scavenging, hydrogen peroxide radical scavenging and ferric ion reducing capacity compared to the emulsion $(\mathrm{p} \leq 0.05)$. In addition, the emulsion had a better metal chelating activity compared to the extract $(\mathrm{p} \leq 0.05)$. Okra mucilage may have reduced the antioxidant activity of the extract suggesting its incongruity in this emulsion formulation.
\end{abstract}

Key words: Antioxidant, emulsion, formulation, mucilage.

\section{Introduction}

Pharmaceutical formulations are stable preparations comprising of the active pharmaceutical ingredient (API) and the excipients that ensure that the API is released at the right time and to the proper site of action. Excipients are inert ingredients that impact desirability on these preparations either as bulking agents, fillers, viscosity imparting agents, lubricants, anti-adherents, sweeteners, colorants, binders, disintegrants, emulsifying agents, suspending agents and so on (Aulton and Taylor, 2017). Excipients not only serve to increase the palatability of pharmaceutical dosage forms but also fulfil multiple roles such as to increase serum drug bioavailability, delay drug release to reduce adverse effects and ensure exact API delivery to specific site of drug action (Jaimini and Kothari, 2012). In these preparations, the excipients serve to increase the weight, patient acceptability and consistency of the formulation (Avachat et al., 2011). Excipients range widely in nature. They may be but not limited to inert carbohydrates, naturally occurring sugars, synthetic mineral salts, water, naturally occurring oils, mineral oils, naturally occurring mineral matter and preservatives. Majority of excipients are derived from synthetic or semi-synthetic sources that may be expensive to source. Hence, it is needed to use cheaper naturally sourced excipients. Natural

Corresponding author: Joseph O. Oiseoghaede, Phone: +2348098253426, Email: joseph.oise14@gmail.com, joiseoghaede@unilag.edu.ng

DOI: https://doi.org/10.3329/bpj.v24i1.51631 
excipients are mostly derived from plants and minerals. The most widely used natural excipients are gums and mucilages because of their multiple roles in formulations. A natural gum or mucilage may act as a binder and disintegrant in the same formulation. Examples include Acacia gum which may serve as a binder because of its adhesive properties but at the same time, absorbs water from the surrounding medium to facilitate break up of a tablets. In the same formulation, it may also serve as a wetting agent because of its hydrophilicity thus aiding the drug dissolution, absorption and bioavailability in the circulation. However, because of the multipurpose use of this Acacia gum, it is in high demand in the pharmaceutical industry, thus this has increased its price in the market. Due to the exorbitant prices of these gums, there is a need for use of more affordable and suitable alternatives to function in pharmaceutical formulations. Okra is a natural thickener obtained from pods of Abelmoschus esculentus (L.) Moench (Fam. Malvaceae) are used to prepare soups for consumption with staple meals. It is a vegetable grown in tropical and sub-tropical regions of the world but is indigenous to North East Africa especially Ethiopia and Sudan (Gemede et al., 2013). Okra mucilage has been used as a binder and retardant in sustained-release diclofenac tablets (Naveen et al., 2013). It also caused sustained-release of propranolol hydrochloride in tablet dosage forms (Zaharuddin et al., 2014). Okra mucilage was also used to retard the release of naproxen sodium tablets at 1-5\% concentration (Hussain et al., 2017). It was also used to formulate a stable oil-in-water emulsion of n-hexadecane at acidic pH (Ghori et al., 2014). Okra mucilage is made up of a polysaccharide that consists of galactose, rhamnose and galacturonic acid subunits with some acetylation (Hussain et al., 2017). Herbal preparations are in increasing use by many people in the world (WHO, 2013) and while practitioners make their formulations, they prefer the use of multi-component natural herbs and vegetables (Oiseoghaede et al., 2016). Spondias mombin L. (Fam. Anacardiaceae) is a small deciduous tree that grows in humid tropical climates (Castner et al., 1998). The leaves are rich in vitamins such as ascorbic acid, niacin, riboflavin and thiamine as well as tannins, saponins and flavonoids which make it a very strong antioxidant (Igwe et al., 2010). The leaves have been shown to contain $19.35 \mathrm{mg} / 100 \mathrm{~g}$ ascorbic acid (Njoku and Akumefula, 2007) which makes it a good candidate for this study. This study aims to evaluate effect of $A$. esculentus mucilage on antioxidant property of $S$. mombin extract in a formulated emulsion of the extract with the mucilage used as the emulsifying agent using various in vitro antioxidant assays. The study was also designed to physically and microscopically characterize formulated emulsion, perform phytochemical screening on the mucilage and assess if emulsion to be formulated can be fit for therapy against human oxidative conditions.

\section{Materials and Methods}

Chemicals and reagents: Potassium ferricyanide, trichloroacetic acid, ferric chloride (Sigma Aldrich Germany) 1,1-diphenyl-2-picrylhydrazyl (DPPH) crystals and orthophenanthroline (Merck KGaA, Darmstadt, Germany) were purchased from source as indicated. Phosphate buffer (0.1M, pH 7.4), phosphate buffer ( $\mathrm{pH}$ 6.6) and ethanol were prepared at and obtained from Department of Pharmacognosy laboratories, University of Lagos. Absolute ethanol and methanol (EMD Milliform Corporation, Germany) and Rhodamine B dye (Macklin Industries, Shanghai, China) were purchased while hydrogen peroxide (20 volume) used was a standard proprietary product bought off the shelf.

Plant collection, identification and preparation: Plants were purchased from Ijegun market, Lagos state, Nigeria in August and September 2019. Okra pods and $S$. mombin leaves were authenticated at the Department of Botany, University of Lagos where the plants were assigned voucher specimen number LUH 6203 and 8999, respectively. Voucher specimens were then deposited at the herbarium. The plant materials were garbled, cleaned and dried in the oven at $72 \mathrm{~h}$, powdered and stored in air-tight containers until needed for the study $(\mathrm{Ng}$ et al., 2012). 
Extraction of plant materials: $770.22 \mathrm{~g}$ of powdered Okra pods were transferred into a container with $500 \mathrm{ml}$ distilled water, heated at $60^{\circ} \mathrm{C}$ and continuously stirred for approximately $4 \mathrm{~h}$. The concentrated solution was filtered through a muslin cloth for several times and cooled to room temperature. Extracted gum was isolated by precipitating in absolute ethanol. The isolated gum was placed in several steel containers and dried to attain a constant weight at $35-45^{\circ} \mathrm{C}$ in hot air oven. The mucilage was then powdered and stored in dry containers (Kulkarni et al., 2002). S. mombin leaves were cleaned then dried in the oven (Ng et al., 2012). $1246.55 \mathrm{~g}$ of powdered leaf was macerated in 101 of $70 \%$ ethanol in an amber colored Winchester bottle for $72 \mathrm{~h}$ after which the clear filtered ethanol extract was concentrated in the rotary evaporator set at $45^{\circ} \mathrm{C}$ to dryness. The yield of extract was calculated in relation to the dried plant materials.

Phytochemical screenings: The Okra mucilage extract was subjected to qualitative chemical investigation to test for the presence of various phytochemicals using standard procedures and reagents (Sofowora, 1993).

Emulsion formulation: The emulsion of the test material was formulated by using the following formula.

$\begin{array}{ll}\text { S. mombin leaf extract } & 37.5 \% \mathrm{w} / \mathrm{v} \\ \text { Okra mucilage } & 0.5 \% \mathrm{w} / \mathrm{v} \\ \text { Methyl cellulose } & 0.5 \% \mathrm{w} / \mathrm{v} \\ \text { Liquid paraffin } & 20 \% \mathrm{v} / \mathrm{v} \\ \text { Distilled water to } & 100 \mathrm{ml}\end{array}$

This was done using a modified Forbes method (Suthar and Barbhaiya, 2015). 1g of the mucilage and methylcellulose were weighed and transferred into the mortar and triturated by a pestle till a fine powder was formed. $75 \mathrm{mg}$ S. mombin was weighed and transferred into a beaker and gradually dissolved with a minute quantity of distilled water and warmed till an appreciable quantity dissolved. The resulting mixture was then filtered and filtrate transferred into the mortar in aliquots and triturated till a homogenous mixture was formed. 40mls liquid paraffin was added in little quantities till a homogenous paste was observed. This was then transferred into a calibrated bottle and distilled water added to the mark. The bottle was also shaken to ensure proper emulsification. This is equivalent to $0.375 \mathrm{mg} / \mathrm{ml} \quad(37.5 \%)$ solution. Emulsion was refrigerated and reconstituted for use. Serial dilutions with methanol were made from this emulsion for use in the assays.

Preparation of S. mombin aqueous stock solution: $200 \mathrm{mg}$ of the $S$. mombin extract was weighed using an analytical balance and transferred into a beaker and gradually dissolved with a minute quantity of distilled water and warmed till an appreciable quantity dissolved. The resulting mixture was filtered, and the filtrate was made up to $200 \mathrm{ml}$ with distilled water. This is equivalent to $1 \mathrm{mg} / \mathrm{ml}$ $(100 \%)$ solution and was used as representative of the aqueous fraction of $S$. mombin. This was then refrigerated until used. This concentration $(1 \mathrm{mg} / \mathrm{ml})$ was used because it had comparable antioxidant activity with ascorbic acid at the same concentration as evidenced in a previous study (Ogunye, 2018). Serial dilutions were made with methanol from this preparation for use in the assays.

\section{Characterization of emulsion}

Microscopy: $0.35 \mathrm{~g}$ water-soluble Rhodamine B dye was weighed and dissolved in $100 \mathrm{ml}$ distilled water. A 1:1 solution of the emulsion and the diluted dye was prepared and a drop of the mixture was placed on a slide and covered with a cover slip. It was mounted on a microscope and viewed at $\mathrm{x} 10$ and $\mathrm{x} 40$ objective.

Micrometry: The size of oil globules of the already mounted emulsion-dye mixture above was measured using an already calibrated eyepiece micrometer $(1$ division $=2.4 \mu \mathrm{m}) .10$ globules were measured and grouped into small, medium and large sized granules. Mean size each globule group was calculated and expressed as mean size \pm standard deviation (SD).

Measurement of pH: $30 \mathrm{ml}$ of $S$. mombin $-A$. esculentus emulsion was measured in measuring cylinder and transferred into a beaker to test for its 
$\mathrm{pH}$ using a $\mathrm{pH}$ meter. The same procedure was repeated for $S$. mombin stock solution.

\section{Antioxidant assays}

$D P P H$ free radical scavenging activity: The antioxidant activity of the extract was evaluated based on the radical scavenging effect of the stable 1, -diphenyl-2-picrylhydrazyl (DPPH)-free radical activity by a method employed by Blois (1958). The extracts $(0.0125-0.2 \%)$ were prepared from the stock solution using suitable dilution. $0.1 \mathrm{mM}$ of DPPH was prepared in methanol and $1 \mathrm{ml}$ of this solution was mixed with $3 \mathrm{ml}$ of sample solution in test tubes in triplicates. Absorbance was measured at $517 \mathrm{~nm}$ using UV-VIS Spectrophotometer. Methanol (3 ml) with DPPH solution $(0.1 \mathrm{mM}, 1 \mathrm{ml})$ was used as control. This was also repeated for the emulsion. Methanol was used as blank. \% inhibition was calculated using the following equation.

\section{Inhibition of DPPH $=\left(A_{C}-A_{A}\right) / A_{C} \times 100 \%$}

Where $A_{C}$ is the absorption of the control sample and $\mathrm{A}_{\mathrm{A}}$ is the absorption of tested extract (Eruygur et al., 2017).

Hydrogen peroxide scavenging assay: This was carried out by a method employed by Gayathri et al. (2014). The extracts $(3 \mathrm{ml})$ were prepared in methanol at various concentrations $(0.0125-0.2 \%)$ and mixed with $1.8 \mathrm{ml}$ of $40 \mathrm{mM}$ hydrogen peroxide prepared in phosphate buffer $(0.1 \mathrm{M}, \mathrm{pH} 7.4)$ and incubated for $10 \mathrm{~min}$. The absorbance of the solution was taken at $230 \mathrm{~nm}$ against blank solution containing phosphate buffer without hydrogen peroxide. The experiments were carried out in triplicates. This was also repeated for the emulsion.

$\%$ Inhibition $=\left(\mathrm{A}_{\mathrm{C}}-\mathrm{A}_{\mathrm{A}}\right) / \mathrm{A}_{\mathrm{C}} \times 100 \% \quad$ Eq. 2

Where $A_{C}$ is the absorption of the control sample and $\mathrm{A}_{\mathrm{A}}$ is the absorption of tested extract.

Ferric ion reducing antioxidant capacity: Using a modified method as employed by Adesegun et al. (2009), ferric ion reducing capacity of the extract solution and emulsion was assessed. The extracts (0.0125-0.2\%) in $0.5 \mathrm{ml}$ of methanol was mixed with phosphate buffer $(0.25 \mathrm{ml}, \mathrm{pH} 6.6)$ and potassium ferricyanide $(0.25 \mathrm{ml} \mathrm{1 \%})$. The mixture was incubated at $50^{\circ} \mathrm{C}$ for $20 \mathrm{~min}$. A portion $(0.5 \mathrm{ml})$ of trichloroacetic acid (10\%) was added to the mixture, which was then centrifuged at $1600 \mathrm{~g}$ for $10 \mathrm{~min}$. The upper layer of the solution was mixed with distilled water $(0.5 \mathrm{ml})$ and $\mathrm{FeCl}_{3}(0.1 \mathrm{mls}, 1 \%)$ and the absorbance was measured at $700 \mathrm{~nm}$. The experiments were carried out in triplicates and also done for the extracts. Increased absorbance of the reaction mixture indicated increased reducing power.

Metal chelating activity: The reaction mixture contain $1 \mathrm{ml} 0.05 \%$ orthophenanthroline in methanol, $2 \mathrm{ml}$ ferric chloride $200 \mu \mathrm{M}$ and $2 \mathrm{ml}$ of various concentrations $(0.0125-0.2 \%)$ of the solution and emulsion. The mixture was incubated at ambient temperature for $10 \mathrm{~min}$, and then the absorbance of the same was measured at $510 \mathrm{~nm}$. The chelated iron formed a red chromophore in solution and an increase in absorbance indicated increased activity. The experiment was performed in triplicate (Qureshi et al., 2010).

Statistical analysis: All tests were done in triplicates and analyzed using Microsoft Excel expressed as mean \pm standard deviation (SD) and compared using Repeated Measures (RM). Two-way Analysis of Variance (ANOVA) by GraphPad prism 8 Software as well as Bonferroni multiple comparison post-test were used to compare against the $S$. mombin solution. Differences between assay results were assessed at $95 \%$ confidence interval ( $\mathrm{p} \leq$ $0.05)$.

\section{Results and Discussion}

Extract yield: The yields of A. esculentus anpethercentage inhibition v S. mombin extracts were $25.75 \%$ and $2.31 \%$, respectively as shown on Table 1 . The high yield of the $S$. mombin leaves was expected because the extracting solvent was highly polar and would extract the abundant polar constituents of the S. mombin leaves. The yield of the $S$. mombin was similar to that reported by hydroethanolic extraction of the leaves in a similar study which recorded $23.5 \pm 4.4 \%$ yield (Cristofoli et al., 2018). However, the mucilage yield was quite low compared to a recent study that used 
similar method but different precipitating solvent, acetone (Farooq et al., 2013). The yield was $11.44 \%$ w/w which was over 4-fold the yield obtained in this study. The large difference may be attributable to the different solvents used.

Phytochemical screening: The mucilage was observed to contain terpenoids, reducing sugars, carbohydrates and unsaturated lactones and lacked saponins, alkaloids, flavonoids, tannins, deoxysugars and anthraquinones as shown on Table 2. In a related study, it was seen to contain only carbohydrates similar to this study (Kumar et al., 2009). It also had similar results in that it also lacked saponins, alkaloids, flavonoids, tannins and deoxysugars. In contrast, this study showed presence of terpenoids, reducing sugars and unsaturated lactones. The presence of carbohydrates and reducing sugars corresponds to work done by some researchers (Farooq et al., 2013). Deoxysugars and unsaturated lactones are hallmark of cardiotonic glycosides. However, unsaturated lactones were present and deoxysugars were absent in this study.

Table 1. Calculation of yield of extract.

\begin{tabular}{llll}
\hline Plants & Dry plant material $(\mathrm{g})$ & Extract $(\mathrm{g})$ & $\%$ Yield \\
\hline Abelmoschus esculentus & 770.22 & 17.78 & 2.31 \\
Spondias mombin & 1246.55 & 320.94 & 25.75 \\
\hline
\end{tabular}

Table 2. Results of phytochemical screening of mucilage.

\begin{tabular}{|c|c|c|c|c|c|c|c|c|c|c|c|c|}
\hline \multirow[t]{2}{*}{ Sample } & \multirow[t]{2}{*}{ Saponins } & \multirow[t]{2}{*}{ Alkaloids } & \multirow[t]{2}{*}{ Terpenoids } & \multirow[t]{2}{*}{ Tannins } & \multirow[t]{2}{*}{ Shinoda } & \multirow[t]{2}{*}{ Fehling's } & \multirow{2}{*}{$\begin{array}{l}\text { Keller- } \\
\text { Killiani }\end{array}$} & \multicolumn{3}{|c|}{ Borntrager's } & \multirow[t]{2}{*}{ Kedde's } & \multirow[t]{2}{*}{ Molisch } \\
\hline & & & & & & & & Free & $\mathrm{O}$ & $\mathrm{C}$ & & \\
\hline AEM & - & - & + & - & - & + & - & - & - & - & + & + \\
\hline
\end{tabular}

+ = present, - = absent; $\mathrm{AEM}=$ A. esculentus mucilage.

Emulsion stability: Stability of formulations is critical to prevent coalescence and phase separation. Utilization of an oil phase that will stabilize the $S$. mombin extract is crucial in formulation development. Liquid paraffin emulsion BP was utilized as the base formulation with the dual suspending agent capacity of $A$. esculentus mucilage and methyl cellulose. A concentration of $0.5 \% \mathrm{w} / \mathrm{v} A$. esculentus extract and $0.5 \%$ methylcellulose led to a $1 \% \mathrm{w} / \mathrm{v}$ total suspending agent concentration. Herbexcipient interaction may have led to the perceived decrease in the antioxidant effect of the S. mombin extract. This occurred due to formation of globules with increased integrity in the emulsion that did not optimally release the $S$. mombin active responsible for anti-oxidant activity. The formulation however exhibited high stability.

Microscopy, micrometry and $\mathrm{pH}$ measurement: Microscopy revealed the emulsion as an oil-in-water emulsion with the background taking the color of the water-soluble Rhodamine dye and the yellow to brown colored oil globules on the foreground as observed in Figure 1. Micrometry showed that the oil globules were majorly of the small-sized type with average size of $4.8 \mu \mathrm{m}$. The size range of globules was 4.8-21.6 $\mu \mathrm{m}$ as seen on Table 3 . This is identical with what was reported in literature with size ranges from 6-23 $\mu \mathrm{m}$ (Ghori et al., 2014). The $\mathrm{pH}$ measurement gave a value of slightly acidic $\mathrm{pH}$ of 6.88 as seen on Table 4 which was very close to neutral and may be considered safe as it may not cause gastric ulceration associated with acidic $\mathrm{pH}$. Emulsification was at slightly acidic $\mathrm{pH}$ comparable to what was seen in literature $(\mathrm{pH} 3)$ as reported by Ghori et al. (2014).

\section{Antioxidant assays}

DPPH radical percentage inhibition: A concentration-dependent increase in DPPH radical 
scavenging activity was observed for both extract and emulsion as seen in Table 5. The extract and emulsion had comparable DPPH activity at $0.0125 \%$, $\mathrm{p} \leq 0.05(\mathrm{p}>0.05)$. However at $0.025 \%$, the extract was a better DPPH radical scavenger than the emulsion, $\mathrm{p} \leq 0.05$ ( $\mathrm{p} \leq 0.01)$. This trend was maintained between $0.05-0.2 \%$ with the extract having better DPPH activity than the emulsion, $\mathrm{p} \leq$ $0.05(\mathrm{p} \leq 0.0001)$. This means that the extract was a better DPPH radical scavenger than the emulsion (formulated with the mucilage), due to entrapment of the extract globules in the emulsion matrix (Ilomuanya et al., 2018). This indicated that the introduction of the mucilage in the formulation reduced the DPPH activity of the extract. The DPPH activity exhibited however is still adequate for its use as an antioxidant preparation.

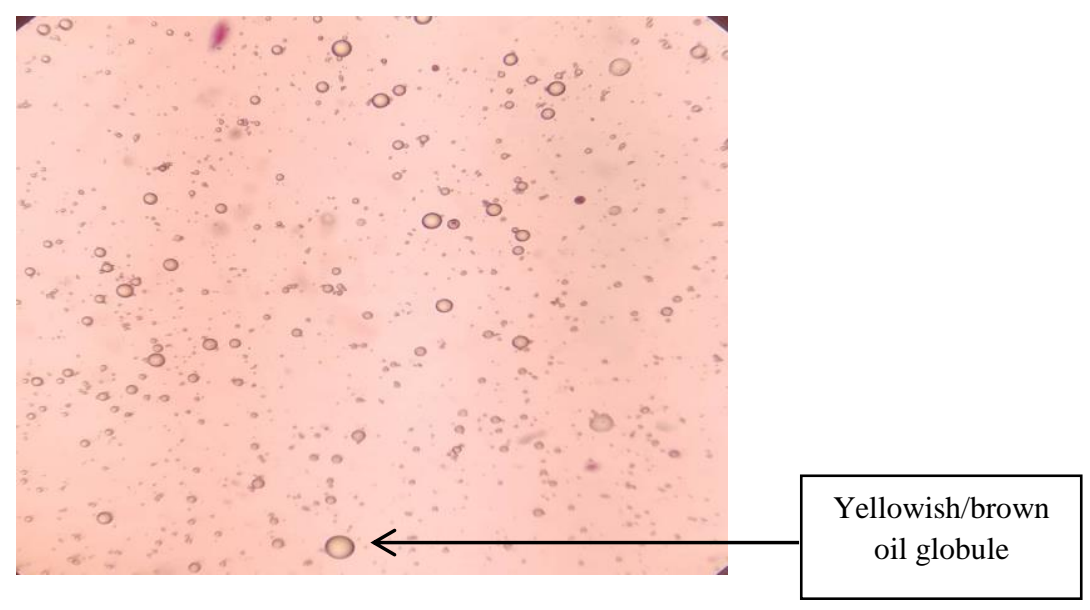

Figure 1. Microscopic study of S. mombin - A. esculentus mucilage emulsion oil globules (x 100).

Table 3. Micrometric studies.

\begin{tabular}{lccc}
\hline Size & Range size (No. of divisions) & No. of globules & Mean size \pm SD $(\mu \mathrm{m})$ \\
\hline Small & $1-3$ & 6 & $4.80 \pm 2.16$ \\
Medium & $4-6$ & 3 & $11.20 \pm 1.39$ \\
Large & $7-9$ & 1 & $21.60 \pm 0.00$ \\
\hline
\end{tabular}

Table 4. Measurement of $\mathrm{pH}$.

\begin{tabular}{lc}
\hline Sample & $\mathrm{pH}$ \\
\hline S. mombin solution & 3.87 \\
S. mombin - A. esculentus emulsion & 6.88 \\
\hline
\end{tabular}

Table 5. Percentage inhibition in DPPH assay at $517 \mathrm{~nm}$.

\begin{tabular}{llllll}
\hline Concentration & 0.0125 & 0.025 & 0.05 & 0.1 & 0.2 \\
\hline S. mombin solution & $27.17 \pm 2.78$ & $46.09 \pm 4.05$ & $61.30 \pm 5.42$ & $85.39 \pm 1.45$ & $88.76 \pm 0.29$ \\
S. mombin - A. esculentus emulsion & $28.50 \pm 5.60^{\mathrm{a}}$ & $25.26 \pm 1.60^{\mathrm{c}}$ & $18.91 \pm 6.36^{\mathrm{e}}$ & $39.29 \pm 2.52^{\mathrm{e}}$ & $40.12 \pm 7.79^{\mathrm{e}}$ \\
\hline
\end{tabular}

Data expressed as mean $\pm \mathrm{SD}$ at 5 concentrations, $n=3 ;{ }^{\mathrm{e}}=$ Significantly different from $S$. mombin solution at $p \leq 0.05$ $(p \leq 0.0001) ;{ }^{c}=$ Significantly different from S. mombin solution at $p \leq 0.05(p \leq 0.01) ;{ }^{a}=$ Not significantly different from $S$. mombin solution at $p \leq 0.05(p>0.05)$. 
Hydrogen peroxide radical scavenging inhibition: There was a concentration-dependent decrease in hydrogen peroxide radical scavenging activity for both extract and emulsion as seen in Table 6. This is an abnormal trend as there should be an increase in activity as concentration increases but this was the reverse. The extract had a better hydrogen peroxide radical scavenging at $0.0125 \%$ and $0.1 \%, p \leq 0.05(\mathrm{p} \leq 0.001)$ and at $0.025 \%$ and $0.05 \%, \mathrm{p} \leq 0.05$ ( $\mathrm{p} \leq 0.0001)$. However, they had statistically similar activity at $0.2 \%, \mathrm{p} \leq 0.05$ ( $\mathrm{p}>$ $0.05)$. The extract still had better activity than the emulsion at $0.2 \%$. This implies that the extract was a better hydrogen peroxide radical scavenger than the emulsion (formulated with the mucilage). This indicated that the introduction of the mucilage in the formulation also diminished the hydrogen peroxide radical scavenging activity of the extract. This negative activity observed in both extract and emulsion showed they may not be suitable for use in scavenging hydrogen peroxide radicals.

Ferric ion reducing capacity: A concentrationdependent increase in reducing capacity was observed as represented on Table 7. The extract and emulsion exhibited similar activity at $0.0125-0.1 \%, \mathrm{p}$ $\leq 0.05$ ( $\mathrm{p}>0.05)$ but extract had better activity than emulsion at $0.2 \%, p \leq 0.05(\mathrm{p} \leq 0.05)$. Thus, it can be deduced that at lower concentration the activities of extract and emulsion are similar but extract had better activity at high concentration. This also suggests that the use of the mucilage as emulsifier in the formulation caused a decline in the ferric ion reducing capacity of the extract because the extract still had a better activity than the emulsion. However, the reducing capacity of the emulsion will still suffice its use as an antioxidant preparation.

Table 6. Hydrogen peroxide radical scavenging inhibition at $230 \mathrm{~nm}$.

\begin{tabular}{llllll}
\hline Concentration & 0.0125 & 0.025 & 0.05 & 0.1 & 0.2 \\
\hline S. mombin solution & $51.09 \pm 3.05$ & $39.43 \pm 12.12$ & $1.60 \pm 2.79$ & $-63.35 \pm 9.65$ & $-105.21 \pm 5.39$ \\
S. mombin - A. esculentus emulsion & $-41.96 \pm 10.43^{\mathrm{d}}$ & $-83.70 \pm 8.45^{\mathrm{e}}$ & $-132.7 \pm 23.51^{\mathrm{e}}$ & $-152.3 \pm 6.46^{\mathrm{d}}$ & $-118.9 \pm 34.96^{\mathrm{a}}$
\end{tabular}

Data expressed as mean $\pm \mathrm{SD}$ at 5 concentrations, $n=3 ;{ }^{\mathrm{e}}=$ Significantly different from $S$. mombin solution at $p \leq 0.05$ ( $p \leq$ $0.0001) ;{ }^{\mathrm{d}}=$ Significantly different from $S$. mombin solution at $p \leq 0.05(p \leq 0.001) ;{ }^{\mathrm{a}}=$ Not significantly different from $S$. mombin solution at $p \leq 0.05(p>0.05)$.

Table 7. Ferric ion reducing capacity at $700 \mathrm{~nm}$.

\begin{tabular}{llllll}
\hline Concentration & 0.0125 & 0.025 & 0.05 & 0.1 & 0.2 \\
\hline S. mombin solution & $0.206 \pm 0.102$ & $0.287 \pm 0.103$ & $0.355 \pm 0.044$ & $0.559 \pm 0.004$ & $1.194 \pm 0.391$ \\
S. mombin - A. esculentus emulsion & $0.248 \pm 0.001^{\mathrm{a}}$ & $0.466 \pm 0.051^{\mathrm{a}}$ & $0.625 \pm 0.096^{\mathrm{a}}$ & $0.504 \pm 0.062^{\mathrm{a}}$ & $0.667 \pm 0.219^{\mathrm{b}}$ \\
\hline
\end{tabular}

Data expressed as mean \pm SD at 5 concentrations, $n=3 ;{ }^{\mathrm{b}}=$ Significantly different from $S$. mombin solution at $p \leq 0.05$ ( $p \leq$ $0.05) ;{ }^{\mathrm{a}}=$ Not significantly different from $S$. mombin solution at $p \leq 0.05(p>0.05)$.

Table 8. Analysis for metal chelating activity at $510 \mathrm{~nm}$.

\begin{tabular}{llllll}
\hline Concentration & 0.0125 & 0.025 & 0.05 & 0.1 & 0.2 \\
\hline S. mombin solution & $0.034 \pm 0.002^{\mathrm{b}}$ & $0.038 \pm 0.006^{\mathrm{a}}$ & $0.041 \pm 0.002^{\mathrm{c}}$ & $0.056 \pm 0.005^{\mathrm{c}}$ & $0.058 \pm 0.003^{\mathrm{e}}$ \\
S. mombin - A. esculentus emulsion & $0.056 \pm 0.011$ & $0.054 \pm 0.012$ & $0.075 \pm 0.004$ & $0.092 \pm 0.002$ & $0.115 \pm 0.017$ \\
\hline
\end{tabular}

Data expressed as mean \pm SD at 5 concentrations, $n=3 ;{ }^{\mathrm{e}}=$ Significantly different from $S$. mombin solution at $p \leq 0.05$ ( $p \leq$ $0.0001) ;{ }^{c}=$ Significantly different from $S$. mombin solution at $p \leq 0.05(p \leq 0.01) ;{ }^{\mathrm{b}}=$ Significantly different from $S$. mombin solution at $p \leq 0.05(p \leq 0.05) ;{ }^{a}=$ Not significantly different from $S$. mombin solution at $p \leq 0.05(p>0.05)$. 
Metal chelating activity: There was a concentration-dependent increase in metal chelating activity as shown on Table 8 . The extract and emulsion exhibited similar activity at $0.025 \%, \mathrm{p} \leq$ 0.05 ( $\mathrm{p}>0.05$ ). However, this effect was isolated because the emulsion was better than the extract at other concentrations - at $0.0125 \%, \mathrm{p} \leq 0.05$ ( $\mathrm{p} \leq$ $0.05)$, at 0.05 and $0.1 \%, \mathrm{p} \leq 0.05(\mathrm{p} \leq 0.01)$ and at $0.2 \%, \mathrm{p} \leq 0.05$ ( $\leq \leq 0.0001)$. This indicates that inclusion of the mucilage in the formulation increased the metal chelating activity of the extract.

\section{Conclusions}

Naturally sourced plant gums and mucilage have been used in various capacities as excipients in pharmaceutical formulations, including the emulsions. The widely used plant gums and mucilage are however becoming expensive due to their broad acceptance and multipurpose uses in the industry. Hence, a need arises for safe, affordable and viable alternatives. This study has shown that Okra mucilage is a good emulsifier but may have reduced the antioxidant activity of $S$. mombin extract when formulated as emulsion. The emulsion however exhibited good stability and thus can benefit from future studies that would reduce the extract entrapment to increase antioxidant activity. The evidence in this study will direct future research effort at sourcing for other natural plant-based gums and mucilage that can be used in formulating herbal preparations with good drug release and stability profiles.

\section{Acknowledgements}

The authors appreciate the technical support offered by Mr. H.O. Yusuf and Mr. T.I. Adeleke of the Department of Pharmacognosy laboratories, University of Lagos and Mr. S. Adenekan of the Department of Biochemistry laboratories, College of Medicine of the University of Lagos.

\section{Conflict of Interest}

The authors declare no conflict of interest

\section{References}

Adesegun, S.A., Fajana, A., Orabueze, C.I. and Coker, H.A.B. 2009. Evaluation of antioxidant properties of Phaulopsis fascisepala C.B.Cl. (Acanthaceae). Evid.Based Compl. Alt. Med. 6, 227-231,

Aulton, M.E. and Taylor, K. 2017. Aulton's Pharmaceutics: The Design and Manufacture of Medicines, 5th ed. (Illustrated), Elsevier Health Sciences, London, 936p, ISBN (online): 9780702070020.

Avachat, M.A., Dash, R.R. and Shrotriya, S.N. 2011. Recent investigations of plant based natural gums, mucilage and resins in novel drug delivery systems. Indian J. Pharm. Educ. Res. 45, 86-99.

Blois, M.S. 1958. Antioxidant determinations by the use of a stable free radical. Nature 181, 1199-1200,

Castner, J.L., Timme, S.L. and Duke, J.A. 1998. A field guide to medicinal and useful plants of the upper Amazon. Feline Press, Gainesville, Florida, ISBN: 0962515078.

Cristofoli, N.L., Lima, C.A.R., Vieira, M.M.C., Andrade, K.S. and Ferreira, S.R.S. 2018. Antioxidant and antimicrobial potential of cajazeira leaves (Spondias mombin) extracts. Sep. Sci. Technol.

Eruygur, N., Ataş, M., Çevik, Ö. and Tekin, M. 2017. Investigating of phytochemicals, antioxidant, antimicrobial and proliferative properties of different extracts of Thymus spathulifolius Hausskn. and Velen. endemic medicinal plant from Sivas, Turkey. Int. J. Sec. Metab. 4, 155-166.

Farooq, U., Malviya, R. and Sharma, P.K. 2013. Extraction and characterization of okra mucilage as pharmaceutical excipient. Acad. J. Plant Sci. 6, 168172.

Gayathri, G., Bindu, N.R. and Babu, V. 2014. Scavenging of free radicals and total phenols of Methanol extract of Azima tetracantha Lam. Int. J. Pharm. Pharm. Sci. 6, 347-351.

Gemede, H.F., Haki, G.D., Beyene, F., Woldegiorgis, A.Z. and Rakshit, S.K. 2016. Proximate, mineral, and antinutrient compositions of indigenous Okra (Abelmoschus esculentus) pod accessions: implications for mineral bioavailability. Food Sci. Nutr. 4, 223-233.

Ghori, M.U., Alba, K., Smith, A.M., Conway, B.R. and Kontogiorgos, V. 2014. Extracts in pharmaceutical and food applications. Food Hydrocoll. 42, 342-347.

Hussain, A., Qureshi, F., Abbas, N. and Haleem, M.A. 2010. An evaluation of the binding strength of okra gum and the drug release characteristics of tablets prepared from it. Pharmaceutics 9, 8p, DOI: 10.3390/pharmaceutics 9020020 . 
Igwe, C.U., Onyeze, G.O.C., Onwuliri, V.A., Osuagwu, C.G. and Ojiako, A.O. 2010. Evaluation of the chemical compositions of the leaf of Spondias mombin Linn. from Nigeria. Aust. J. Basic Appl. Sci. 4, 706710.

Ilomuanya, M.O., Akhimien, T., Aghaizu, C., Adeyinka, O. and Ajayi, T. 2018. Polyherbal antioxidant topical preparation comprising ethanol extract of Tetracarpidium conophorum and Ocimum gratissimum: formulation and evaluation. Dhaka Univ. J. Pharm. Sci. 17, 213-219.

Jaimini, M. and Kothari, A. 2012. Sustained release matrix type drug delivery system: A Review. J. Drug Deliv. Ther. 2, 142-148.

Kulkarni, T.G., Gowthamarajan, K., Rao, G.B. and Suresh, B. 2002. Evaluation of binding properties of selected natural mucilage. J. Sci. Ind. Res. 61, 529-532.

Kumar, R., Patil, M.B., Patil, S.R. and Paschapur, M.S. 2009. Evaluation of Abelmoschus esculentus mucilage as suspending agent in paracetamol suspension. Int. J. Pharm. Tech. Res. 1, 658-665.

Naveen, G., Naik, V.V., Kumar, G.D. and Samifer, S. 2013. Effect of mucilage of Abelmoschus esculentus as tablet binder in diclofenac sodium matrix tablet. Int. J. Pharm. Chem. Sci. 2, 1320-1323, ISSN: 2277-5005.

Ng, L.Y., Ang, Y.K., Khoo, H.E. and Yim, H.S. 2012. Influence of different extraction parameters on antioxidant properties of Carica papaya peel and seed. Res. J. Phytochem. 6, 61-74.

Njoku, P.C. and Akumefula, M.I. 2007. Phytochemical and nutrient evaluation of Spondias mombin leaves. Pak. J. Nutr. 6, 613-615.
Ogunye, T.O. 2018. In vitro antioxidant activity of Spondias mombin L. (Anacardiaceae) leaves. B. Pharm. Dissertation, University of Lagos, Akoka, Lagos, Nigeria.

Oiseoghaede, J.O., Ajayi, G.A., Odukoya, O.A., Sowemimo, A.A. and Mustapha N.F. 2016. Influence of the areas of specialization of traditional medicine practitioners (tmps) on the types of formulation prescribed in the management of memory loss. Nig. J. Nat. Prod. Med. 20, 35-36,

Qureshi, M.N., Kuchekar, B.S., Logade, N.A. and Haleem, M.A. 2010. In-vitro antioxidant and in-vivo hepatoprotective activity of Leucas ciliata leaves. Rec. Nat. Prod. 4, 124-130.

Sofowora, A. 1993. Screening Plants for Bioactive Agents. In: Medicinal Plants and Traditional Medicine in Africa (Sofowora, A., Ed.), 2nd ed., Spectrum Books Ltd, Sunshine House, Ibadan, pp. 134-156.

Suthar, Y.R. and Barbhaiya, P. 2015. Stability study of liquid paraffin oral emulsion (Cremaffin). Int. J. Pharm. 5, 1242-1247.

World Health Organization. 2013. WHO traditional medicine strategy 2014-2023. WHO Press, Hong Kong SAR, pp. 25-26.

Zaharuddin, N.D., Noordin, M.I. and Kadivar, A. 2014. The Use of Hibiscus esculentus (Okra) Gum in sustaining the release of propranolol hydrochloride in a solid oral dosage form. Bio. Med Res. Int. Article ID 735891, 8 p, DOI: 10.1155/2014/735891. 